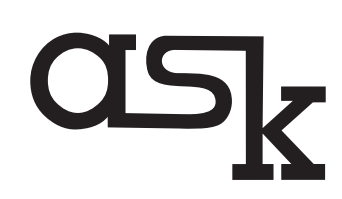

Research \& Methods ISSN 1234-9224, e-ISSN 2544-0799 Vol. 29 (1, 2020): 75-88

The Ohio State University Libraries Columbus, Ohio, USA Institute of Philosophy and Sociology Polish Academy of Sciences, Warsaw, Poland www.askresearchandmethods.org https://doi.org/10.18061/ask.v29i1.0005

\title{
Doing Qualitative Research during the Covid-19 Pandemic of 2020
}

\section{Anna Sedysheva}

The Graduate School for Social Research (GSSR) of the Institute of Philosophy and Sociology of the Polish Academy of Sciences

\begin{abstract}
In this paper I examine how the pandemic and quarantine of 2020 affected qualitative research. Employing personal narrative as a method, I show what disadvantages researchers may have met with whilst conducting their studies. The unprecedented circumstances of the restrictions and uncertainty caused by the Covid-19 crisis have had a dramatic impact on the public mental health of individuals, including academic researchers. Many online tools are very useful for qualitative researchers, but are not a substitute for face-to-face research. In this article I explain these issues more thoroughly and discuss the challenges that researchers have faced during the period of the Covid-19 pandemic.
\end{abstract}

Key words: pandemic, feminist research, mental health

\section{INTRODUCTION}

The pandemic of 2020 has dramatically affected social researchers around the world. Many of us have lost access to sources for data collection, such as archives, libraries and fieldwork locations. It seems that now is an appropriate time to give voice to the effects that the unprecedented circumstances of the pandemic of 2020 have had on researchers such as myself and to analyze this experience. By utilizing this information, support can be given to advancing a methodology on how to conduct research in a time of global crisis. "Many researchers have found the virus interesting and the literature is now getting filled up with information, publications, and updates as the disease is unfolding itself" (Mohanty \& Radhakrishnan, 2020). New measures are also needed to 
provide psychological support for people overcoming personal issues that might complicate their academic work.

I am among the "lucky" group of researchers whose lockdown and selfisolation did not sabotage their work. I did, however, face extreme challenges that $\mathrm{I}$, as a feminist researcher and an empathetic woman, was not prepared to meet while conducting my research. The COVID-19 pandemic has exacerbated many already prevailing health issues. Ryan \& Ayadi (2020) have observed that "we must learn from previous global public health threats to build a gender-responsive, intersectional approach to address immediate and long-term consequences." To elaborate on this, the aspect which is personal to me, I wish to offer my experiences by way of a personal narrative to address how the pandemic of 2020 has affected researchers such as myself and, more generally, the problems of conducting research under this year's challenging conditions. Before employing a personal narrative relating to the 2020 pandemic, however, I wish to elaborate on how I became a feminist researcher and the method of personal narrative itself.

\section{PERSONAL NARRATIVE APPROACH: BECOMING A FEMINIST RESEARCHER}

Doing my research (mostly dedicated to online activism), following and observing how the \#MeToo revolution has developed around the world and how feminist movements began to affect changes in Russia over recent years has both inspired and emboldened me. It has also instilled in me the feeling that the manner in which I present the knowledge of context continues to be affected by my beliefs, my experience, my personality and also my specific view of Russia from abroad, particularly through social media. This has led me to the idea of incorporating a personal narrative in my writings, as such would be relevant for an explanation of my interpretation. Since the 1950s, utilizing personal narratives has become more common in qualitative research. Such narratives contain "a sequence of events" and "usually contains a link to the present on the form of a lesson learnt by the narrator. Narrative analysis seeks to find the link by analyzing and evaluating various parts of the narrative" (Akinsanya \& Bach, 2014).

I was introduced to the narrative method at the London Centre for Interdisciplinary Research. At a workshop during the proceedings of a winter school there, a PhD student from the USA shared some of her own self-reflective writings while doing her research. Such an approach seemed uniquely suited to my situation, as well; one that would enable me to cultivate peace with all three of my identities (as a researcher, as a poet, and as an activist). "By creating our narrative self we also create our history, and therefore gain the ability to narrate not only our own lives but also those surrounding us within our community," by working "to bridge the subjective" (Ricoeur, 1990 in Davis \& Brömdal, 2020). 
Since knowledge is context-dependent and subjectivity is extremely difficult if not impossible to avoid, I began to conceptualize that a narrative method could not only be very useful for me, but also afford me a method that could openly show my values and biases. The narrative approach to writing an introduction for my thesis offered me great relief and taught me how to balance my identities. I realized that they are all integrally connected and the knowledge I am gaining through my continuing research while working on my thesis has always been personal and lifechanging for me, affecting my entire personality.

The words of Dr. Patricia L. Thomson's blog, concerning the narrative method as an introduction to one's research, are herein instructive:

- The personal narrative enacts the (epistemological) position that no research is neutral and all research is written from somewhere, and where matters.

- The personal narrative is intended to show how the research question arises from the personal life or professional work experience of the researcher.

- The personal narrative is intended to lay the groundwork for a claim for professional knowledge. In applied fields, and often in professional doctorates, people draw on their own experience as part of the data.

\section{MY RESEARCH AND JOURNEY INTO FEMINISM}

My research is centered around the \#ЯнеБоюсьСказать (\#IamNotScaredToSpeak) campaign, which took place on Russian-speaking Facebook beginning in Ukraine (See Sedysheva, 2018). It was the first visible, widespread movement in Russia in which women shared their traumatic experiences of sexual assault on social media. My aim is to understand and reconstruct the socio-cultural context related to gender-power relations in contemporary Russia (specifics of 'rape culture'; circumstances of discrimination against women, including gender-based violence; women's protests against dominant 'male' culture) and to present (on the basis of qualitative interviews with key-actors in feminist campaigns) the voices of the feminist community in Russia. Utilizing the \#ЯнеБоюсьСказать (\#IamNotScaredToSpeak) campaign, I am exploring how social media platforms can promote social change and how discourse initiated by this campaign has developed over time, particularly after being reinforced by the \#MeToo movement and various other Russian feminist online campaigns.

My doctoral journey has become a journey of self-discovery; an effort to create new identities and find my bearings. The further along I have gone in the $\mathrm{PhD}$ process as a doctoral student, the more I have struggled with how to present my findings and discoveries without touching upon my personal transformation. 
Feminist qualitative research places much emphasis on "engaging in reflection about the research process" (Ackerly \& True, 2008). As a feminist researcher and a woman, I do not look at women as 'the Other;' since issues discussed by my correspondents are issues that also affect my life. Feminist research aims to create "useful knowledge that will make a difference to women's lives" (Letherby, 2003). As a woman, I have a direct interest in such and any positive changes that affect women.

One of the most challenging aspects for me has been dealing with anger. My research has grown from hoping for social changes in my native land and anger at the ways in which gender inequality affects women in Russia to realizing how negatively I was personally affected by it as well (as a woman who was born and grew up there). Therefore, my research has become important to me as a researcher but also as a person, owing to the period of time over which I have come to understand the enormous foundation that bolsters the patriarchy in society and the gender dictates of such, affecting women in general and, of course, me.

Under certain circumstances qualitative research methodology in social science allows researchers to be deeply and emotionally involved in their research. However, I am ever cognizant of the danger of becoming too influenced by my emotions. I have been writing poetry for more than 15 years and when I was introduced to qualitative research methodology during my MA studies, I began to see a parallel between the two; particularly between poetry and in-depth interviewing. Sociological in-depth interviewing allows a researcher to become immersed in their research, to be companionate, and to almost feel first-hand the experiences of their respondents. This is indirectly akin to what a poet does immersing themselves in an object of study with much empathy, trying to ascertain what it is like to be in someone else's shoes and understanding someone else's pain.

The medical profession is another field in which much emotional labor is an acknowledged part of the job. This emotional labor is part of many roles and consists of how one goes about handling and controlling feelings that can get in the way of accomplishing one's tasks (Hochschild, 1983). Medical students are trained to be able to accentuate the positive for future patients (according to Smith and Kleinman, 1989), and physicians, in particular, have to show sympathy towards their patients. However, as Larson and Yao (2005) have posited, this can be either sincere and deep or more limited and on the surface. A feminist researcher, who is a feminist and also a woman, however, may find it hard to limit her sympathy to the surface level, especially when respondents strike chords that resonate with the researcher's own personal experiences. Social scientists such as Kaufmann (2001) suggest that researchers need to ignore this inclination to really empathize with respondents and that it is better to "completely forget about his/her own opinions 
and mental categories. He/she is supposed to think about only one thing: there is a world to discover, full of hidden treasures." However, this is sometimes easier said than done.

Over time, during the process of conducting interviews, I came to realize how emotionally heavy and challenging they had become for me. I was not only learning about my respondents' experiences. I was uncovering my own traumatic memories, fears and feelings of insecurity. Feminist research is very much about this: uncovering voices that have been ignored, bringing women's perspectives to public discourse, presenting how women actually feel and how their lives are actually lived. The further I studied feminist theory (statistics and studies on violence against women, while collecting material for my discourse analysis) the more I had an urge to speak up myself. The language of my poetry changed first. Then I could no longer stay away from feminist online activism or resist my increasing inclination to react against various governmental discriminatory initiatives against women's rights. Previously, I was more beset with political indifference. Growing up in the Russian Far East during the 1990s and early 2000s, I was a part of a disappointed and isolated society that did not believe in its members' ability to affect political change and thus avoided political participation in the country. During that time, my poetry was more inwardly personal and disconnected from social processes. Throughout my doctoral journey, my discoveries have affected all spheres of my life, including the three identities that have been most important for me: as a researcher, a poet and an activist. It has been challenging to maintain a balance between these three, to deal with my emotions and to react to discourse changes. I could not fully devote myself to my research and ignore my online activism and poetry.

The manner through which I process deep emotions is by writing poetry. I have written more poems when I have been unusually overloaded when writing my essays and papers on violence against women. Concurrently, there is the interesting fact that contemporary feminist poetry in Russia is gaining popularity and visibility. More young women like me are analyzing gender-related issues in their poetry and such poetry may affect public discourse and initiate public debate.

\section{THE IMPACT AND CHALLENGES IN QUALITATIVE DATA COLLECTION DURING THE PANDEMIC OF 2020.}

The emergence of a novel form of coronavirus in China in December 2019, eventually classified as COVID-19, has made 2020 a challenging year for societies in general and the institutions and individuals that are a part of them. Academic institutions have faced considerable challenges as large numbers of academic events were cancelled, before it was possible to organize methods of working 
online. Researchers also faced considerable challenges as individuals and as academics.

Just prior to the imposition of border closings and restrictions concerning movement (during the first half of March), I was conducting fieldwork in Moscow: observing feminist-related events, visiting crisis centers for women, and conducting interviews. Unfortunately, on March 15, I was forced to put all of my plans on hold and return urgently to Poland (where I am a doctoral student), before the borders were closed, owing to fast-moving restrictive measures. Upon arrival back in Poland, I then spent two weeks in obligatory quarantine.

On the one hand, my research work could be still done during the lock-down; however, one important aspect of my research, which is mostly focused on online activism, is the connection between online and offline feminist activities. "Participation in online spaces is a relevant part of daily life and relationships developed within online communities can, and often do, cross the communities' boundaries and affect other aspects of people social life" (Addeo, Paoli et al, 2019), but the pandemic's restrictions clouded this research angle for me.

As a researcher of the Russian-speaking feminist community, I follow various feminist activists on Facebook (this platform is the one commonly used for discussions in post-Soviet spaces by communities interested in change). I have identified the most influential of them (having thousands of followers). Some of them are also journalists who write about issues connected with women's rights. I interviewed activists from different parts of Russia (since my primary focus is on Russia), but I observed the situation in other parts of post-Soviet countries. These interviews will contribute to the empirical part of my $\mathrm{PhD}$ dissertation Project working title: "Social Media Platforms as a New Source for Feminists' Movements. Online Feminist Activism in Russia in 2016-2020."

As is apparent, my research falls mostly into the category of online ethnography or netnography ("the term, based on a combination of the words "internet" and "ethnography" (Addeo, Paoli et al, 2019)). As I mentioned above, I was in Moscow in March of 2020 for my fieldwork. I selected this month because of the large number of feminist events I could attend then (connected to International Women's Day - March 8), but I could not complete my planned fieldwork there, having conducted only about a third of my planned interviews for Moscow. This is how my research became mostly netnographic.

While netnography has many features of classical ethnography, there are some pronounced differences. Researchers Felice Addeo and Angella Delli Paoli (2019) have highlighted the main difference; that "Netnography is easier and far less time-consuming: information can be downloaded from the internet without having to be recorded and transcribed as in the traditional ethnography, the researcher does not have to travel anywhere for data collection." As Kozinets (1998) has 
stated, netnography is "a new qualitative research technique [incorporating text, multimedia and online communication] to study cultures and communities that are emerging through computer-mediated communications"; whereas ethnography is broader, as it includes communication such as body language and other forms of live communication that are less apparent online. My original research plan (to dedicate more time to observe offline activism and analyze the connection between online and offline worlds) was thus made impossible by the pandemic.

\section{ONLINE INTERVIEWS (LEVEL OF TRUST)}

Online interviews have one significant advantage - a researcher can conduct them from any geographic location. However, deeper interpersonal communication and the establishment of a greater level of trust is only possible during a face-to-face meeting. Pleasantries are a large part of putting people at ease when meeting in one's home (Do have a seat on the sofa; That's a nice painting; Your home is very welcoming - as the respondent pets your cat, dog, etc. - or in a public place (Can I get you a cup of tea? Where should we sit? This is a nice place, do you come here often?). With online interviews, this may be replaced with something as simple and impersonal as "Nice to see you, shall we begin?" Without being able to establish some connection, owing to the lack of face-to-face communication with my respondents, I often found it difficult to ascertain or understand the mood of my respondents, and thus was at a disadvantage when trying to avoid or clarify any misunderstandings. Little body language is visible during video interviews. One cannot see what a respondent is doing with their hands, whether there are visible signs of anxiety, whether they are relaxed, or what they may be looking at when their eyes occasionally veer away from their video camera.

The lack of face-to-face exchanges also make follow-up meetings or offers from respondents to participate in something extra less likely. During my fieldwork in Russia, I was invited by one of my participants to attend an anniversary event of "Anna", the oldest Russian crisis center for women. This event was not widely publicized on the internet and I would otherwise have missed it. During the presentation, the attendees were also presented with a book that collected various information on women's rights in Russia and statistics on violence against them. The Russian Federation either does not collect such statistics or at least makes such information impossible to access. The "Anna" Crisis Center presented detailed information that will be very useful for my thesis and I received the previously mentioned book free of charge only because I was conducting my fieldwork offline. During the event, I was also introduced to several activists who I interviewed later.

Another good example of the benefits more likely to accrue from conducting face-to-face interviews concerns the relationship I established with a worker of 
a different crisis center for women. During our meeting in a café, we established a level of trust to the extent that my respondent invited me to visit the secret location of their center (the location is a secret due to potential threats from aggressive partners of women). My visit there was very useful for my research. During informal conversations with several staff members of the center, I learned valuable information that I could use for my research. I also received many recommendations concerning others I should contact for possible interviews. All of the above exchanges would, most likely, have not occurred if I had only been conducting online interviews.

\section{ONLINE INTERVIEWS (TECHNICAL COMPLICATIONS)}

The issues of weak internet connections (low sound, poor sound quality) and various background distractions/noise also make online interviews problematic. I often had to switch between several online platforms to discover one for which the sound quality was acceptable. All such complications contributed to my anxiety and counteracted my being at ease or helping my respondent to be at ease. Unstable internet connections also promoted anxiety. After I conducted an interview that was beset with technical problems, I could not schedule a new one for many days as the fear of new problems would temporarily paralyze me. The repercussions of the 2020 pandemic have also brought forth additional challenges. Firstly, there were problems with scheduling interviews. My participants were women and the lockdown affected many of them, giving them additional work - to take care of children who were withdrawn from schools and added housework in general. With several participants, I re-scheduled our online interview multiple times.

\section{THE ISSUE OF MENTAL HEALTH OWING TO THE PANDEMIC OF 2020}

According to a study on the psychological status and behavioral changes of the general public in China during the first stage of the pandemic, $27.1 \%$ of people experienced depression. The study suggested the need "to pay more attention to public psychological stress, especially among young people, as they are likely to experience anxiety, depression, and psychological abnormalities" (Liu, Luo et al, 2020). This broader issue has been addressed by The World Psychiatric Association. In a report published in July 2020 they highlighted the increasing role of public mental health in the field of psychiatry. "As a result of the COVID-19 pandemic," this report concluded, "a population approach to address this public mental health intervention gap requires even more urgent global attention to prevent the anticipated increased prevalence of mental disorder and poor mental wellbeing" (Campion, Javed et al, 2020). A study by Banks \& Xu (2020) found 
that "Groups with poor mental health before the pandemic experienced the largest deterioration in mental health" (Banks \& Xu in Campion, Javed et al., 2020).

I personally fell into this last category. I have been affected by depression in the past. (My work on the topic of gender violence has also caused me some depression. I have also spoken with a psychologist and a therapist, who prescribed medication for me). The ruining of all my research travel plans, the quarantine and added feelings of uncertainty have all contributed to pushing me toward a deep personal crisis. I was almost completely unable to concentrate at times. On several occasions during my research, owing to my own psychological state, I myself had to postpone interviews with respondents. My diagnosis of depressiveanxiety disorder could not explain what was happening with me. With the help of a psychiatrist, I spotted the problem - I was diagnosed with ADHD. The reason I did not know about this problem and adapted to it was my constant and strict academic schedule. Intuitively, I felt the importance of structure for me. However, when I found myself in a situation of complete uncertainty and anxiety, I was almost unable to conduct any work.

Acknowledging the possibility of some of the above issues, I wish to mention that the administration of my institution - The Institute of Philosophy and Sociology of the Polish Academy of Sciences - provided doctoral students access to free psychological counseling by phone up to twice a week (which I personally did not avail myself of since I have my own therapist). I also had the idea that many others besides me would need help. Whether such help twice a week for all doctoral and master's students would be enough, though, is hard to judge. In addition, there is the factor of how difficult it is for individuals to admit psychological problems and seek help or even just to find the strength to make a call for help. My academic institution also extended the deadline by a month for students to submit their annual report on their academic progress. In my case, however, the additional month only prolonged the state of my anxiety. I cannot say that this extra month made me more productive. Since I could not meet any of my classmates due to quarantine restrictions (with online communication not being an adequate substitute for me), I felt very isolated; especially as a non-native in the country where I am doing my $\mathrm{PhD}$. The feelings of guilt for not being productive enough also contributed to my anxiety and wish to avoid communication with my thesis advisor.

\section{THE IMPACT OF MENTAL HEALTH ON RESEARCH RESPONDENTS OWING TO THE PANDEMIC OF 2020}

Such afflictions and problems are not restricted to the individual though. "Any uncertain situation can lead to panic induced behavior and with the influence of COVID-19, self-confinement and an absence of proper treatment for the infectious 
disease has led masses in panic and anxiety inciting situation" (Lunn et al, 2020), leading to public mental health concerns, such as hysteria (Lunn et al, 2020). Previous studies of SARS have shown that there can be great complications from the restrictions instituted to quarantine people (Xiang in Shuja, Aqeel et al, 2020).

Anxiety was also provoked by the media and controversial news stories. While many psychologists suggested a media detox, in reality it was hard to resist constantly checking on the news. As one of my interview respondents stated, "I know that the news increases my anxiety, but not checking it I feel even more uncertainty." Some studies have highlighted the gendered impact of pandemics (one involving 11,980 people in the UK found that young people and women suffered the greatest in this regard (Banks \& Xu in Campion, Javed et al, 2020)). All of my respondents are female and I had to postpone interviews with several of them due to their depressive state and inability to communicate at a specified time.

As the research I cited above indicates, people with mental health issues before the pandemic were even worse off during it. Many of the respondents who I talked to mentioned problems with mental health predating the pandemic. When speaking about their own experiences, all indicated that activist work took so much of their emotional strength and many of them related how they had sought professional psychological help and were diagnosed with depressive disorders at some time in the past. Some further indicated that their health worsened during the pandemic. However, many of those I did interview remarked on the loneliness they experienced during the lockdown and the burden of new problems. One of my participants related that she felt she was carrying too much of the burden visà-vis other activists in her circle and that she felt others did not appreciate her efforts. Three others respondents shared very personal traumatic stories, such as suicide in the family, a problematic divorce with a husband, and physical abuse from a partner, that influenced their becoming activists. There was a single mother who complained about how the lockdown put extra responsibility for the children on her. Several other activists agreed to a scheduled online interview with me, but then never appeared (and neither apologized nor responded to any further messages from me).

\section{COLLECTING MEDIA SOURCES FOR DISCOURSE ANALYSIS}

As researcher Marija Topuzovska Latkovilkj specified about problems that may arise while gathering data online, "the need of evaluation for the accuracy/ trustworthiness of the online sources, the need for internet access, limited access of some data bases or high-cost data access, the contrast between very fresh and very redundant data available, irrelevant data" (Latkovikj \& Popovska, 2020). Nevertheless, my research focusing on women's activism and women's rights 
indicates that the pandemic has affected women dramatically. The UN Women website (on a special web page featuring news about women's rights during the COVID-19 pandemic) has noted that "[i]n times of crisis, when resources are strained and institutional capacity is limited, women and girls face disproportionate impacts with far reaching consequences" and that "[h]ard-fought gains for women's rights are also under threat" (UN Women, 2020).

According to data on The Forum for Research on Eastern Europe and Emerging Economies website (Berlin, 2020), the ways that women have been affected by the pandemic of 2020 may have repercussions that are more long-lasting than those affecting men. The service sector jobs losses that may take a long time recovering from are more commonly occupied by women. In Russia, for instance, according to the Russian Statistical Agency (Rosstat), " $49 \%$ of all employed women in 2019 worked in three sectors - trade, healthcare, and education" (Kuzmina 2020). There is also the issue of domestic violence, a direct consequence of quarantine conditions, which increases the time spent by the potential victim and abuser in a closed space, and the inability to seek immediate help, both psychological and medical (Kuzmina 2020).

News on how women's rights around the world are being violated during the pandemic is extremely disturbing. As the increase in cases of domestic violence became more visible in media sources, the issue of choosing relevant data became more crucial. My data became very rich, too much to be analyzed by one researcher. It is still hard for me to complete coding of the large quantity of material that I have collected. My respondents who deal with victims of domestic violence confirmed that many Russian women are in very dangerous situations, and I have the impression that the news of women's tragedies is coming from many places at the same time.

Maintaining emotional stability during my research has always been challenging for me. However, during the years prior to 2020 I was more optimistic and could focus on the rapid expansion and achievements of the feminist community in Russia. This year's crisis, however, brings into question those achievements. Being a feminist researcher and a woman in Poland during a time of crisis has also affected me. Poland's parliament has again sought to push "a controversial proposal to tighten abortion laws." "This legal proposal has caused me additional anxiety, especially as a married woman in Poland during a time of closed borders.

One more relevant issue for me as a post-Soviet woman was the political protests that have become common in Belarus. Belarus is the center of attention for postSoviet countries now. The country could develop a new scenario for overthrowing their illegitimate president, Alexander Lukashenko. The protest movement that has arisen there is also a symbol of women's solidarity, since the three leaders of that movement are females. 2020 is not just a year of a global pandemic, but also a year of significant social and political challenges. 


\section{CONCLUSION}

The time of a global pandemic has created challenges for educational institutions and researchers (especially younger ones). On the one hand, online spaces can provide new tools for social research and data collection. My personal experience, however, has highlighted possible problems with conducting online interviews: unstable internet connections, difficulties in establishing levels of trust and the avoidance of miscommunication; psychological problems connected with anxiety and depression in times of uncertainty; and the possible low motivation of participants. Graduate students have flexibility to work on their own. However, in times of uncertainty, isolation might negatively affect the mental health of researchers and their productivity might suffer.

\section{DISCUSSION AND SUGGESTIONS FOR POSSIBLE CHANGES}

The experience of a global pandemic has highlighted the need to create a psychological support system to help graduate students overcome stressful circumstances in the future, so that science will continue to have more young and able contributors. Owing to stress and anxiety during the pandemic, knowing how to stay productive is an issue which is relevant not only for this researcher. I have faced many difficulties (as indicated above), but many of them could easily have been faced by researchers in different fields. The issue of emotional detachment in the field of feminist research may have its particular aspects, but the issues of mental health are far more universal and can affect graduate students doing research in any field.

To better support other researchers in the future, a different form of collaboration between students and academia might be in order. Perhaps some online activities could be organized (not only lectures, but some entertainment or cultural events, discussions and reading clubs), so that graduate students would feel less isolated.

It might be helpful, as well, for academic staff to check in with students via video calls to monitor students' state of mind on a regular basis; email is not sufficient. Regular video calls by supervisors, administrators or student representatives could help academia become more attuned to effectively react in the event that students need psychological support. I believe that weekly anonymous questionnaires about psychological health are also necessary, so that each institution's administration would be more aware of this and be able to react appropriately to students' needs.

Institutions, if they do not offer it already, ought to budget for providing financial help to students and employees for accessing psychological help. A good first step might be a mentoring program that students who believe themselves to be in good mental health (after some basic training) can run; a volunteer organization on campus to reach out to other students during all sorts of trying times as and when they arise in the future (as well as being available for students even during "normal" times). Last 
but not least, academic institutions should offer new graduate students a seminar or series of lectures on personal mental health and how to manage emotional issues when doing research with people face-to-face. Many institutions now offer lectures on intellectual property infringement and conducting research in an ethical way. Now is the time to add various mental health issues to such curriculums.

\section{NOTES}

1 https://www.theguardian.com/world/2020/apr/14/concerns-over-polish-governmenttightening-abortion-laws-during-covid-19-crisis

\section{REFERENCES}

Ackerly, B., \& True, J. (2008). Reflexivity in Practice: Power and Ethics in Feminist Research on International Relations. International Studies Review, 10(4), 693-707. https://doi.org/10.1111/j.1468-2486.2008.00826.x

Addeo, F., Paoli, A. D., Esposito, M., \& Bolcato, M. Y. (2019). Doing Social Research on Online Communities: The Benefits of Netnography. Athens Journal Of Social Sciences, 7(1), 9-38. https://doi.org/10.30958/ajss.7-1-1

Akinsanya, A., \& Bach, C. (2014). Narrative analysis: The Personal Experience Narrative approach. In American Society for Engineering Education 2014 Zone I Conference. Retrieved from http://www.asee.org/

Berlin, M. P. (2020, November 15). Domestic Violence in the Time of Covid-19 • FREE NETWORK. Retrieved from https://freepolicybriefs.org/2020/10/12/domesticviolence-covid-19/

Campion, J., Javed, A., Sartorius, N., \& Marmot, M. (2020). Addressing the public mental health challenge of COVID-19. The Lancet Psychiatry, 7(8), 657-659. https:// doi.org/10.1016/S2215-0366(20)30240-6

Davis, I., \& Brömdal, A. (2020). A Critical Investigation of Masculinity in Education. Advances in Early Childhood and K-12 Education Inclusive Theory and Practice in Special Education, 288-300. https://doi.org/10.4018/978-1-7998-2901-0.ch014

Green, J., Willis, K., Hughes, E., Small, R., Welch, N., Gibbs, L., \& Daly, J. (2007). Generating best evidence from qualitative research: The role of data analysis. Australian and New Zealand Journal of Public Health, 31(6), 545-550. https://doi. org/10.1111/j.1753-6405.2007.00141.x

Hochschild, A. R. (1983). The managed heart: The commercialization of human feeling. Berkeley: University of California Press

Jain, M., Mohanty, C., \& Radhakrishnan, R. (2020). Re-exploring the online surveys: Research tools in COVID times. Journal of Anaesthesiology Clinical Pharmacology, O(0), 0. https://doi.org/10.4103/joacp.JOACP_401_20

Kaufmann, J. C. (2001). The Comprehensive Interview. Paris, Nathan Université.

Kuzmina, O.(2020, May 18). Covid-19 and Gender Inequality in Russia - FREE NETWORK. Retrieved September 21, 2020, from https://freepolicybriefs. org/2020/05/14/covid-19-gender-inequality-russia/ 
Larson, E. B. (2005). Clinical Empathy as Emotional Labor in the Patient-Physician Relationship. Jama, 293(9), 1100-1106. https://doi.org/10.1001/jama.293.9.1100

Latkovikj, M. T., \& Popovska, M. B. (2020). Online research about online research: Advantages and disadvantages. E-methodology, 6(6), 44-56. https://doi.org/10.15503/ emet2019.44.56

Letherby, G. (2003). Feminist Research in Theory and Practice. Buckingham: Open University Press.

Liu, X., Luo, W. T., Li, Y., Li, C. N., Hong, Z. S., Chen, H. L., Xiao, F., \& Xia, J. Y. (2020). Psychological status and behavior changes of the public during the COVID-19 epidemic in China. Infectious diseases of poverty, 9(1), 58. https://doi.org/10.1186/ s40249-020-00678-3

Lunn, P. D., Belton, C. A., Lavin, C., Mcgowan, F. P., Timmons, S., \& Robertson, D. A. (2020). Using Behavioral Science to help fight the Coronavirus. Journal of Behavioral Public Administration, 3(1). https://doi.org/10.30636/jbpa.31.147

Public Mental Health Briefing on Covi-19 (07.2020)

Ryan, N. E., \& Ayadi, A. M. (2020). A call for a gender-responsive, intersectional approach to address COVID-19. Global Public Health, 15(9), 1404-1412. https:// doi.org/10.1080/17441692.2020.1791214

Sedysheva, A. (2018). The \#Янебоюсьсказать (\#Iamnotscaredtospeak) Campaign Of July 2016 In Facebook'S Russian Speaking Community: A Discourse Analysis. Praktyka Teoretyczna, 180-202. https://doi.org/10.14746/prt.2018.4.7

Shuja, K. H., Aqeel, M., Jaffar, A., \& Ahmed, A. (2020). Covid-19 Pandemic And Impending Global Mental Health Implications. Psychiatria Danubina, 32(1), 32-35. https://doi.org/10.24869/psyd.2020.32

Smith, A., \& Kleinman, S. (1989). Managing Emotions in Medical School: Students' Contacts with the Living and the Dead. Social Psychology Quarterly. https://doi. org $/ 10.2307 / 2786904$

Thomson, P. L. (2016, February 22). The personal narrative in the thesis introduction. Retrieved December, from https://patthomson.net/2016/02/22/the-personalnarrative-in-the-thesis-introduction/

Un Women, accessed 15.01.2020 https://interactive.unwomen.org

UN Women: How Covid Impacts Women and Girls. (2020). Retrieved from https:// interactive.unwomen.org/multimedia/explainer/covid19/en/index.html

Walker, S. (2020, April 14). Concerns over Polish government tightening abortion laws during Covid-19 crisis. Retrieved September 21, 2020, from https://www. theguardian.com/world/2020/apr/14/concerns-over-polish-government-tighteningabortion-laws-during-covid-19-crisis 